\title{
ARTICLE
}

\section{The Radioactivity and Dose Assessment of Radioacarbon and Tritium in Graphite Waste Samples of the KRR-2}

\author{
Hee Reyoung Kim* and Geun Sik Choi \\ Korea Atomic Energy Research Institute, Daejeon, 305-600, Republic of Korea
}

\begin{abstract}
The radioactivity of ${ }^{14} \mathrm{C}$ and ${ }^{3} \mathrm{H}$ in graphite samples from the dismantled Korea Research Reactor-2 (the KRR-2) site was analyzed by high-temperature oxidation and liquid scintillation counting, and the graphite waste was suggested to be disposed of as a low-level radioactive waste. The graphite samples were oxidized at a high temperature of 800 degrees centigrade, and their counting rates were measured by using a liquid scintillation counter (LSC). The combustion ratio of the graphite was about $99 \%$ on the sample with a maximum weight of $1 \mathrm{~g}$. The recoveries from the combustion furnace were around $100 \%$ and $90 \%$ in ${ }^{14} \mathrm{C}$ and ${ }^{3} \mathrm{H}$, respectively. The minimum detectable activity was $0.04-0.05 \mathrm{~Bq} / \mathrm{g}$ for the ${ }^{14} \mathrm{C}$ and $0.13-0.15 \mathrm{~Bq} / \mathrm{g}$ for the ${ }^{3} \mathrm{H}$ at the same background counting time. The dose calculation was carried out from its radioactivity analysis results. The dose estimation gave a higher annual dose than the domestic legal limit for a clearance. It was thought that the sampled graphite waste from the dismantled research reactor was not available for reuse or recycling and should be monitored as low-level radioactive waste.
\end{abstract}

\section{KEYWORDS: radioactivity of ${ }^{14} \mathrm{C}$ and ${ }^{3} \mathrm{H}$, graphite, KRR-2, LSC, annual dose, disposal}

\section{Introduction}

The KRR-1\&2 were operated for more than 30 years and have been stopped since 1995. The KRR-2 facilities, which had a capacity of $1 \mathrm{MW}_{\text {th }}$, were completely dismantled as of 2008. Graphite waste with the weight of about seven tons was generated during dismantling. Graphite was used as a moderator (thermal column) in the KRR-2 reactor and irradiated by thermal neutron. Apart from the nuclear reactor core, graphite is one of the main sources of radioactivity. Due to its large volume, graphite is expected to comprise of considerable amounts of low and intermediate radioactive waste. The radioactivity of the thermal column graphite comes from various nuclides including beta nuclides such as ${ }^{3} \mathrm{H},{ }^{14} \mathrm{C},{ }^{63} \mathrm{Ni},{ }^{56} \mathrm{Fe},{ }^{36} \mathrm{Cl},{ }^{90} \mathrm{Sr}$; gamma nuclides such as ${ }^{152} \mathrm{Eu}$, ${ }^{137} \mathrm{Cs},{ }^{60} \mathrm{Co}$; and others. Especially, most of the radioactivity is known to be from ${ }^{14} \mathrm{C}$ and ${ }^{3} \mathrm{H}^{1-3)}$, which are released as a gas state from the graphite waste. ${ }^{14} \mathrm{C}$ is produced in the graphite of the reactor from reactions of ${ }^{13} \mathrm{C}(\mathrm{n}, \gamma){ }^{14} \mathrm{C},{ }^{14} \mathrm{~N}(\mathrm{n}$, $\mathrm{p}){ }^{14} \mathrm{C}$ and ${ }^{17} \mathrm{O}(\mathrm{n}, \alpha){ }^{14} \mathrm{C}$. The ${ }^{14} \mathrm{~N}(\mathrm{n}, \mathrm{p}){ }^{14} \mathrm{C}$ reaction is the dominant contributor to ${ }^{14} \mathrm{C}$ because of its high neutron reaction cross-section and abundance of ${ }^{14} \mathrm{~N}{ }^{3)} \cdot{ }^{3} \mathrm{H}$ in the graphite is originated from the reactions ${ }^{6} \mathrm{Li}(\mathrm{n}, \alpha)^{3} \mathrm{H},{ }^{2} \mathrm{H}(\mathrm{n}$, $\gamma)^{3} \mathrm{H}$, and ${ }^{3} \mathrm{He}(\mathrm{n}, \mathrm{p})^{3} \mathrm{H}$, where the ${ }^{6} \mathrm{Li}(\mathrm{n}, \alpha)^{3} \mathrm{H}$ is the main reaction due to its very high neutron activation cross-section and high neutron flux in the graphite thermal column ${ }^{3)}$. A high concentration of $3 \mathrm{H}$ has been reported in reactor graphite. In the present work, the radioactivity of the ${ }^{14} \mathrm{C}$ and ${ }^{3} \mathrm{H}$ of the dismantled KRR-2 is analyzed by high-temperature combustion and a liquid scintillation counting method. Its annual dose calculation is carried out for internal exposures such as inhalation and ingestion where the pure beta emitting

*Corresponding Author, Tel: +82-42-868-2048, Fax: +82-42-8631289, E-mail: kimhr@kaeri.re.kr nuclides, ${ }^{14} \mathrm{C}$ and ${ }^{3} \mathrm{H}$, have dominant effects.

\section{Method}

\section{Experimental Equipments and chemicals}

A high-temperature combustion furnace (GAU, UK) was used for the oxidation of the graphite samples. A Quantulus TM 1220 liquid scintillation counter (LSC, PerkinElmer Inc, Wallac Oy, Turku, Finland) was employed for the measurement of ${ }^{3} \mathrm{H}$ and ${ }^{14} \mathrm{C}$. $\mathrm{HNO}_{3}$ and Carbo $\mathrm{Sorb}^{\mathrm{R}} \mathrm{E}$ were used for absorbing tritium $\left({ }^{3} \mathrm{H}\right)$ and radiocarbon $\left({ }^{14} \mathrm{C}\right)$ where the tritium exists as $\mathrm{HTO}$ and radiocarbon as $\mathrm{CO}_{2}$. Ultima Gold LLT Cocktail was used as a scintillation cocktail.

\section{Sample preparation}

The graphite thermal column consists of many stringers with a constant cross-section. Those were stacked in alternating layers with a direction towards the core and perpendicularly to that direction. The thermal column had a width of $3,350 \mathrm{~mm}$, a length of $1,220 \mathrm{~mm}$, and a height of $1,000 \mathrm{~mm}$. The zones of the thermal column for sampling were divided into 4 regions where a region $A$ was the nearest one from the surface of the reactor core (Fig.1). In this experiment, to obtain the radioactivity surrounding the reactor core surface, four graphite samples were collected from a region A of the graphite thermal column of the KRR-2, although the remains should usually be sampled. The size of the sampled graphite was $1 \mathrm{~cm} \times 1 \mathrm{~cm}$ so that the quarts boat, in which the sample was placed, could cover it. Four samples weighed about $1 \mathrm{~g}$ each.

\section{Analysis procedure}

As is seen in Fig. 2, the graphite samples were oxidized in the high-temperature furnace rates and were measured by using the $\mathrm{LSC}^{4}$. 


\subsection{Pretreatment}

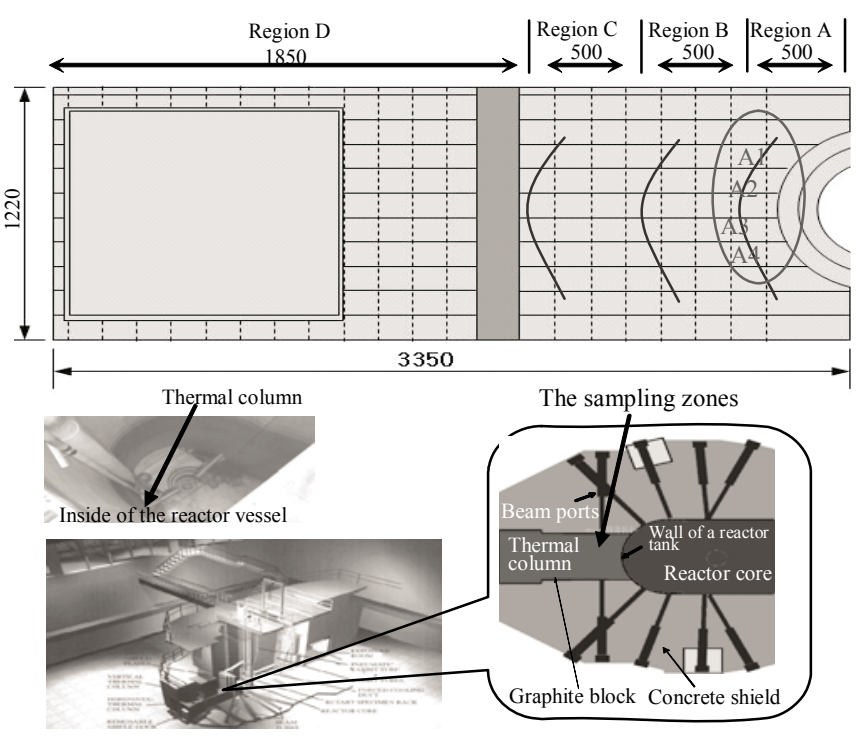

Fig. 1. Graphite thermal column of the KRR-2 and sampling points

The $1 \mathrm{~g}$ graphite samples were placed into the boat and oxidized in the quarts glass combustion tube where the combustion duration was 6 hours, and the temperature of the sample zone was a maximum of $500{ }^{\circ} \mathrm{C}$. The $0.5 \%$ Pt-alumina catalyst was used for better oxidation. ${ }^{3} \mathrm{H}$ and ${ }^{14} \mathrm{C}$ were trapped in the bubblers of the $\mathrm{HNO}_{3}$ solution and Carbo Sorb, respectively. Then the $20 \mathrm{~mL}$ vials with the cocktailed solution, in which the ratio of the $\mathrm{HNO}_{3}$ solution and Ultima G.S. was 8:12 and that of Carbo sorb and Ultima G.S. was $5: 15$, were placed into the LSC deck for counting.

\subsection{Measurement of ${ }^{14} \mathrm{C}$ and ${ }^{3} \mathrm{H}$ by LSC}

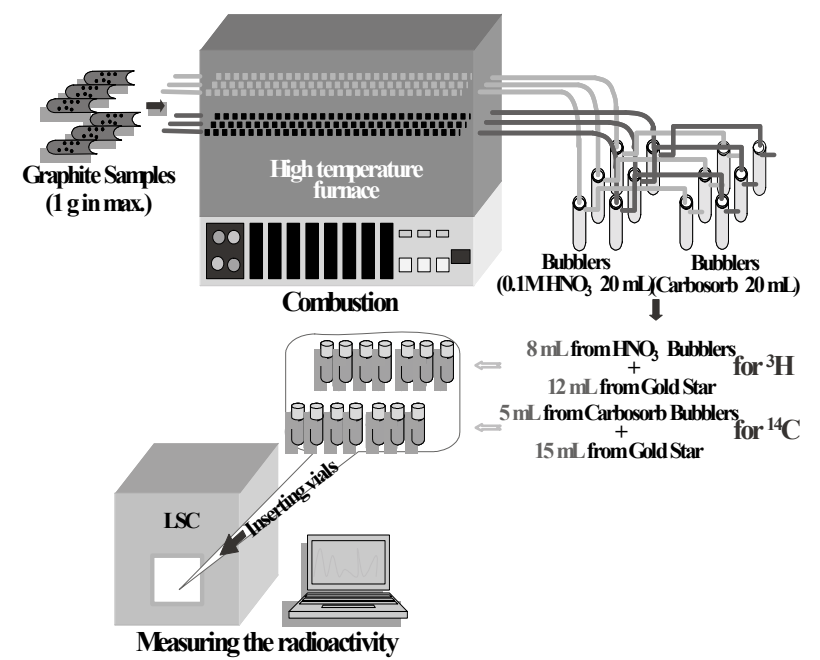

Fig. 2. The experimental system with a commercialized furnace and an LSC for measuring the ${ }^{14} \mathrm{C}$ and ${ }^{3} \mathrm{H}$ radioactivity

A high-energy beta nuclide window mode and low-energy beta nuclide window mode were used for the measurement of ${ }^{14} \mathrm{C}$ and ${ }^{3} \mathrm{H}$ in the LSC (Wallac 1220 Quantulus TM), respectively. The samples and blank were counted for 90 minutes and 3 cycles. The averages and standard deviation of 3 cyclic counts were calculated. On the other hand, the counting efficiency was measured by using an external standard method (SQPE) at different quench level as is represented, in Fig. 3. The counting efficiencies were measured to be $25-34 \%$ for ${ }^{14} \mathrm{C}$ and $54-64 \%$ for ${ }^{3} \mathrm{H}$. On the other hand, the furnace recovery was measured by using reference materials of ${ }^{14} \mathrm{C}$ and ${ }^{3} \mathrm{H}$.

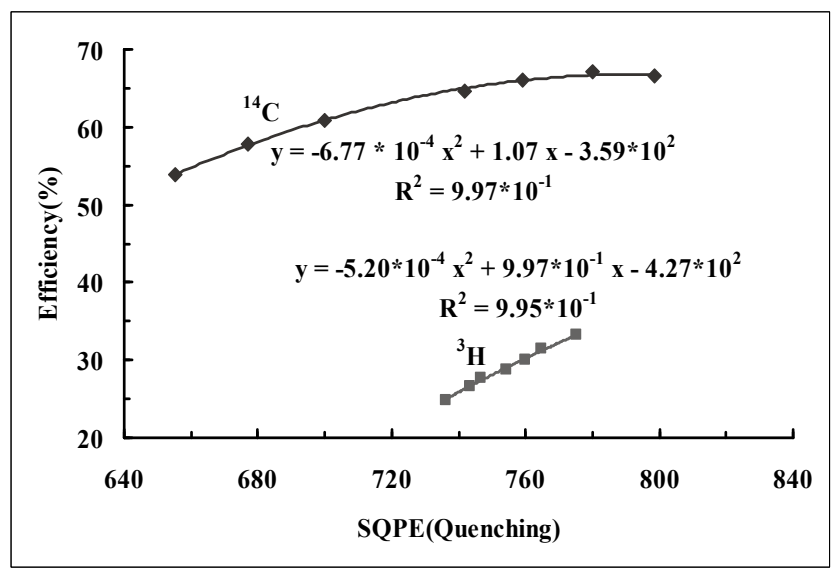

Fig. 3. Counting efficiency of ${ }^{14} \mathrm{C}$ and ${ }^{3} \mathrm{H}$ for different quench levels (SQP(E))

\subsection{Experimental uncertainty}

Some experimental or systematic factors were considered to cause the measurement uncertainty ${ }^{5-7)}$. First of all, weighing the samples and bubbler solution could cause experimental errors due to poor measurements. The recovery of the furnace and the efficiency of the LSC could be considered as other factors for the errors as well.

For the present analysis, because the measurement errors could be assumed to be independent of each other and the presentation of the radioactivity had a product form as presented in equation (1), its combined relative uncertainty could be expressed in the form of equation (2) through some mathematical process ${ }^{4-7)}$.

$$
\begin{aligned}
\qquad A_{S}=\frac{C-B}{60} \times \frac{100}{E} \times \frac{1}{m} \times \frac{m_{f}-m_{t}}{m_{s}} \times \frac{100}{R} \\
\left(\frac{U_{A_{S}}}{A_{S}}\right)^{2}=\left(\frac{U_{C-B}}{C-B}\right)^{2}+\left(\frac{U_{E}}{E}\right)^{2}+\left(\frac{U_{m}}{m}\right)^{2}+\left(\frac{U_{m_{f}-m_{t}}}{m_{f}-m_{t}}\right)^{2}+\left(\frac{U_{m_{s}}}{m_{s}}\right)^{2}+\left(\frac{U_{R}}{R}\right)^{2} \\
\text { As } \quad=\text { The activity concentration in the sample }(\mathrm{Bq} / \mathrm{g}) \\
\mathrm{C} \quad=\text { The sample count rate }(\mathrm{CPM}) \\
\mathrm{B} \quad=\text { The background count rate }(\mathrm{CPM}) \\
\mathrm{E} \quad=\text { The counter efficiency (\%) } \\
\mathrm{m} \quad=\text { The mass of the bubbler solution taken for analysis }(\mathrm{g}) \\
\mathrm{m}_{\mathrm{f}}=\text { The final bubbler mass (g) } \\
\mathrm{m}_{\mathrm{t}}=\text { The bubbler tare mass }(\mathrm{g}) \\
\mathrm{m}_{\mathrm{s}}=\text { Mass of sample taken }(\mathrm{g}) \\
\mathrm{R} \quad=\text { Furnace recovery (\%) } \\
\mathrm{U}_{\mathrm{As}}=\text { The uncertainty of the activity concentration in the } \\
\quad \text { sample (Bq/g) }
\end{aligned}
$$




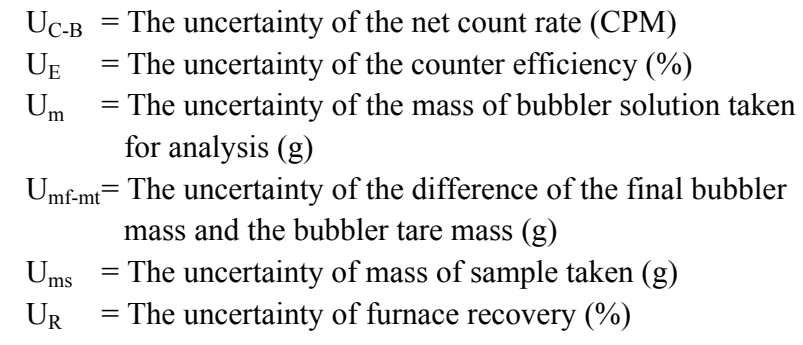

\subsection{Dose assessment}

The individual effective dose rate estimation was important for the determination of recycling or reuse. Because ${ }^{14} \mathrm{C}$ and ${ }^{3} \mathrm{H}$ are pure beta emitters, internal exposures such as inhalation and ingestion has an influence on a dose estimation. The conversion factors of ${ }^{14} \mathrm{C}$ and ${ }^{3} \mathrm{H}$ are presented in Table $\mathbf{1 .}$

Table 1. The conversion factor for an effective dose calculation.

\begin{tabular}{ccc}
\hline Nuclides & Inhalation $(\mathrm{Sv} / \mathrm{Bq})$ & Ingestion $(\mathrm{Sv} / \mathrm{Bq})$ \\
\hline${ }^{3} \mathrm{H}$ & $1.7 \times 10^{-11}$ & $1.7 \times 10^{-11}$ \\
${ }^{14} \mathrm{C}$ & $6.4 \times 10^{-12}$ & $5.6 \times 10^{-10}$ \\
\hline
\end{tabular}

The dose was calculated by using equations (3) and (4) based on the IAEA's recycle or reuse scenario ${ }^{8}$.

$$
\begin{gathered}
H_{I N G}=t D F_{I N G} W\left(I C_{I N G}+I 2 T F_{I N G} C_{s}\right) \\
H_{I N H}=V t D F_{I N H} W\left(C_{d} C_{w}+C_{s} R F T F_{I N H}\right)
\end{gathered}
$$

$\mathrm{H}_{\mathrm{ING}} \quad=$ The effective dose equivalent from one year's intake by ingestion $(\mathrm{Sv} / \mathrm{y})$

$\mathrm{t}=$ The duration of exposure for the individual $(\mathrm{h})$

$\mathrm{DF}_{\mathrm{ING}}=$ The dose conversion factor from ingestion $(\mathrm{Sv} / \mathrm{Bq})$

$\mathrm{W}=$ The fraction of the material handled (1.0 in this analysis)

I $\quad=$ The rate of secondary ingestion of removable contamination $(0.01 \mathrm{~g} / \mathrm{h}$ in this analysis $)$

I2 $=$ The rate of secondary ingestion of removable surface contamination $\left(10^{-4} \mathrm{~m}^{2} / \mathrm{h}\right.$ in this analysis)

$\mathrm{TF}_{\mathrm{ING}}=$ The transfer factor for the ingestion of surface activity (0.01 in this analysis)

$\mathrm{TF}_{\mathrm{INH}}=$ The transfer factor for the inhalation of surface activity $\left(10^{-6}\right.$ in this analysis $)$

$\mathrm{C}_{\mathrm{ING}}=$ The concentration of the radionuclide $(\mathrm{Bq} / \mathrm{g})$

$\mathrm{C}_{\mathrm{s}} \quad=$ The concentration present as surface contamination ( $1 \mathrm{~Bq} / \mathrm{cm}^{2}$ in this analysis)

$\mathrm{H}_{\mathrm{INH}}=$ The committed effective dose equivalent from one year's intake by inhalation (Sv)

$\mathrm{V}=$ The ventilation rate $\left(1.2 \mathrm{~m}^{3} / \mathrm{h}\right.$ in this analysis $)$

$\mathrm{DF}_{\mathrm{INH}}=$ The dose conversion factor from inhalation $(\mathrm{Sv} / \mathrm{Bq})$

$\mathrm{C}_{\mathrm{d}} \quad=$ The concentration of respirable dust in air $(0.001$ $\left.\mathrm{g} / \mathrm{m}^{3}\right)$

$\mathrm{C}_{\mathrm{w}} \quad=$ The concentration of the radionuclide $(\mathrm{Bq} / \mathrm{g})$

$\mathrm{RF}=$ The resuspension factor for surface activity $\left(10^{-6} \mathrm{~m}^{-1}\right.$ in this analysis)

$$
\begin{aligned}
\mathrm{TF}_{\mathrm{INH}}= & \text { The transfer factor for the inhalation of surface } \\
& \text { activity }\left(10^{-6} \text { in this analysis }\right)
\end{aligned}
$$

\section{Results and discussion}

The $1 \mathrm{~g}$ graphite samples were almost completely combusted under the oxidation temperature of $500{ }^{\circ} \mathrm{C}$. There were little visible remains in the boats of four samples after a 6-hour combustion where the combustion ration was more than $99 \%$. The furnace recoveries were $100 \% \pm 5 \%$ and $90 \% \pm 5 \%$ for ${ }^{14} \mathrm{C}$ and ${ }^{3} \mathrm{H}$, respectively. The background counting rates, which were generally dependent on the counter, the energy range of ${ }^{14} \mathrm{C}$ and ${ }^{3} \mathrm{H}$, the quench level, the vial for the LSC, and the radioactivity level of the blank sample, were 3-4 CPM for ${ }^{14} \mathrm{C}$ and 1.5-2 CPM for ${ }^{3} \mathrm{H}$, respectively, where a polyethylene vial was used. Net count rates were calculated by subtracting the background count rate from the sample count rate. The analytical results for the ${ }^{14} \mathrm{C}$ and ${ }^{3} \mathrm{H}$ in graphite samples are shown in Table 2.

Table 2. The radioactivity of ${ }^{14} \mathrm{C}$ and ${ }^{3} \mathrm{H}$ in graphite samples from the thermal column of the KRR-2

\begin{tabular}{ccccc}
\hline \multirow{2}{*}{ Sample } & \multicolumn{2}{c}{${ }^{14} \mathrm{C}(\mathrm{Bq} / \mathrm{g})$} & \multicolumn{2}{c}{${ }^{3} \mathrm{H}(\mathrm{Bq} / \mathrm{g})$} \\
\cline { 2 - 5 } & Mean $\pm \mathrm{SD}$ & $\mathrm{RSD}(\%)$ & Mean $\pm \mathrm{SD}$ & $\mathrm{RSD}(\%)$ \\
\hline A1 & $(8.68 \pm 0.86) \times 10^{2}$ & 0.49 & $(3.53 \pm 0.29) \times 10^{1}$ & 0.50 \\
$\mathrm{~A} 2$ & $(1.14 \pm 0.10) \times 10^{3}$ & 0.45 & $(1.03 \pm 0.95) \times 10^{2}$ & 0.43 \\
A3 & $(8.07 \pm 0.70) \times 10^{2}$ & 0.46 & $(2.86 \pm 0.29) \times 10^{2}$ & 0.44 \\
A4 & $(4.64 \pm 0.40) \times 10^{2}$ & 0.50 & $(1.85 \pm 0.19) \times 10^{1}$ & 0.47 \\
\hline
\end{tabular}

The activity of ${ }^{14} \mathrm{C}$ was higher than that of ${ }^{3} \mathrm{H}$ over all samples with the activity ratios of the ${ }^{14} \mathrm{C}$ to ${ }^{3} \mathrm{H},{ }^{14} \mathrm{C} /{ }^{3} \mathrm{H}$, being between 2.8 and 25 . The relative standard deviations were less than about $0.5 \%$ for the radioactivity of the four samples. Also, it was thought that the large difference in the radioactivity between the samples, in spite of the similar 50$\mathrm{cm}$ radius from the reactor core was due to the inhomogeneous distribution of nitrogen and lithium in the graphite samples. Therefore, more sampling from different locations of the graphite block is perhaps needed, and a radioactivity analysis should be carried out for more exact inventory estimation of ${ }^{14} \mathrm{C}$ and ${ }^{3} \mathrm{H}$. On the other hand, the minimum detectable activities (MDA) by using these background counting rates were $0.04-0.05 \mathrm{~Bq} / \mathrm{g}$ for ${ }^{14} \mathrm{C}$ and $0.13-0.15 \mathrm{~Bq} / \mathrm{g}$ for ${ }^{3} \mathrm{H}$, each based on Curie's equation. Curie's equation ${ }^{9)}$ is defined as Eq. (5);

$$
\mathrm{MDA}=\frac{2.75+4.65 \sqrt{N_{b}}}{t \times E \times R \times m}
$$

where $\mathrm{N}_{\mathrm{b}}$ is the count of the background, $\mathrm{t}$ is the background counting time (second), $\mathrm{E}$ is the counting efficiency, $\mathrm{R}$ is a recovery of the furnace, and $\mathrm{m}$ is the weight of a sample $(\mathrm{g})$. So, the MDA depends on the background counts, counting time, and the weight of the sample. In this work, the counts of the sample were much higher than those of the blank. In 
relation with the experimental uncertainty, it was expected that the background counting rate had little effect on the uncertainty of the radioactivity of the sample. As other factors causing an uncertainty in this work, the relative uncertainty of a sample weighing, the mass of a bubbler solution taken for an analysis, and the difference between the final bubbler mass and the bubbler tare mass were $0.01 \%$, $0.05 \%$, and $0.03 \%$ respectively, in this experiment. The relative uncertainty of the decay correction and certified ${ }^{14} \mathrm{C}$ and ${ }^{3} \mathrm{H}$ standard solution (as quoted on certificate) were $0.2 \%$ and $0.67 \%$, respectively. The relative uncertainty of the furnace recovery was $4.9 \%$, and that of the liquid scintillation counter calibration curve was $1.0 \%$. In addition, the counting uncertainty of the measurement by using an LSC was less than $0.5 \%$, as was determined its relative standard deviation. Therefore, the combined relative uncertainty was calculated to be less than $5.1 \%$. While investigating the components of the uncertainty, the uncertainty of the furnace recovery was found to be a dominant factor for causing an experimental uncertainty. In fact, this recovery considerably depended on the condition of the Pt catalyst, temperature, and burning duration. Hence, it was thought that this uncertainty could be remarkably reduced by carrying out an exchange of the catalyst and the maintenance of the suitable temperature and duration.

The annual dose was calculated conservatively where the exposure time was 24 hours a day, which is 8,760 hours a year, as was seen in Table 3. The dose estimation indicated that the internal exposure by ingestion was much higher than that by inhalation. The ingestion from ${ }^{14} \mathrm{C}$ contributes more than $99 \%$ to the total internal dose. If the external exposure effect by gamma radionuclides like ${ }^{60} \mathrm{Co},{ }^{134} \mathrm{Cs}$, and ${ }^{152} \mathrm{Eu}$ included in the graphite samples were added, the total dose will be higher.

Table 3. Effective dose by using IAEA's recycle and reuse scenario

\begin{tabular}{ccc}
\hline Nuclides & Inhalation $(\mu \mathrm{Sv} / \mathrm{y})$ & Ingestion $(\mu \mathrm{Sv} / \mathrm{y})$ \\
\hline${ }^{3} \mathrm{H}$ & $0.00331 \sim 0.0511$ & $0.0290 \sim 0.427$ \\
${ }^{14} \mathrm{C}$ & $0.0312 \sim 0.0767$ & $22.8 \sim 56.0$ \\
Total & \multicolumn{2}{c}{$22.9 \sim 56.2$} \\
\hline
\end{tabular}

These figures are much higher than the legal limit of an annual dose rate for clearance, $10 \mu \mathrm{Sv} / \mathrm{y}{ }^{10)}$. This meant that the specific activity of ${ }^{14} \mathrm{C}$ and ${ }^{3} \mathrm{H}$ corresponding to $10 \mu \mathrm{Sv} / \mathrm{y}$ should be much lower than those of the present work. In fact, gamma radionuclides like ${ }^{60} \mathrm{Co}$ and ${ }^{152} \mathrm{Eu}$ are also included in graphite where ${ }^{60} \mathrm{Co}$ is a dominant factor for a dose estimation. So, they should be considered together for a practical dose estimation which includes external and internal effects. Especially, ${ }^{60} \mathrm{Co}$ causes a strong external exposure as well as the fact that its internal dose conversion factor is 3,000 times as high as ${ }^{14} \mathrm{C}$. After all, the graphite samples of this work could not have clearance, and so it is impossible for them to be reused or recycled for other industrial purposes. On the other hand, when it was considered that the radioactivity in the graphite thermal column was decreased inversely proportional to the square of the distance from the reactor core, the annual dose due to ${ }^{14} \mathrm{C}$ and ${ }^{3} \mathrm{H}$ of regions $\mathrm{B}$, $\mathrm{C}$, and $\mathrm{D}$ was calculated to be $6 \sim 14 \mu \mathrm{Sv} / \mathrm{y}, 3 \sim 6 \mu \mathrm{Sv} / \mathrm{y}$, and less than $3 \mu \mathrm{Sv} / \mathrm{y}$, respectively. Therefore, the determination on the clearance in these regions was possible by carrying out the actual sampling and dose estimation including other radionuclides of the graphite thermal column as well as ${ }^{14} \mathrm{C}$ and ${ }^{3} \mathrm{H}$

\section{Conclusion}

The radioactivity of ${ }^{14} \mathrm{C}$ was higher than that of ${ }^{3} \mathrm{H}$ from the analysis of the high-temperature combustion and the LSC method. It was understood that the experimental error was mainly due to a furnace. The dose from the present analysis was higher than the legal limit of an annual dose for clearance, $10 \mu \mathrm{Sv} / \mathrm{y}$. The dose estimation due to the ${ }^{14} \mathrm{C}$ and ${ }^{3} \mathrm{H}$ radionuclides indicated that the graphite waste from the present sampled region of the thermal column of KRR-2 had difficulty in reuse or recycling, although the dose effect by other nuclides including gamma emitting ones was not estimated.

\section{Acknowledgment}

This project has been carried out under the nuclear research and development program supported by the Ministry of Education, Science and Technology, Republic of Korea.

\section{References}

1) Bisplinghoff, B., Lochny, M., Fachinger, J., Brucher, H., "Radiochemical characterization of graphite from Julich experiment reactor (AVR)," Nuclear Energy 39[5], 311 (1999).

2) Heung N. Lee, et al., "Determination of C-14 and H-3 in Radioactive Wastes by Oxidation Method," Proc. Korean Nuclear Society Autumn Meeting, Kyungu, Korea, Oct. 28-29, 2004, 757 (2004).

3) Xiaolin Hou, "Rapid analysis of ${ }^{14} \mathrm{C}$ and ${ }^{3} \mathrm{H}$ in graphite and concrete for decommissioning of nuclear reactor," Applied Radiation and Isotopes, 62, 871 (2005).

4) Ian Croudace and Jung-Suk Oh, Analysis of total tritium and ${ }^{14} \mathrm{C}$ in solid samples, GAU/RC/2022, National Oceanography Centre, (2005).

5) Robert J. Moffat, "Describing the Uncertainties in Experimental Results," Experimental Thermal and Fluid Science, 1, 3 (1988).

6) James D. Jenkins, Measurement Uncertainty Analysis Fundamentals, Quametec Corporation, Brighton, 1 (2004).

7) Hugh W. Coleman and W. Glenn Steele, Experimentation and Uncertainty Analysis for Engineers, John Willey and Sons, New York, 1 (1999).

8) IAEA, Application of Exemption Principles to the Recycle and Reuse of Materials from nuclear Facilities, IAEA Safety Series No. 111-P-1.1, IAEA, Vienna, 97 (1992).

9) IAEA, Measurement of Radionuclides in Food and the Environment, Technical Report Series No. 295, International Atomic Energy Agency (IAEA), (1989).

10) MEST Notice 2008-64, Ministry of Education, Science and Technology (MEST), (2008). 